\title{
Facility Management Challenges and Opportunities in the Malaysian Property Sector
}

\author{
Syed Abdul Haris bin Syed Mustapa \& Hamimah Adnan \\ Department of Quantity Surveying \\ Faculty of Architecture, Planning \& Surveying \\ Universiti Teknologi MARA, Shah Alam, Selangor. Malaysia \\ Tel: 60-3-5544-4935 E-mail: hamimah689@salam.uitm.edu.my \\ Kamaruzaman Jusoff (Corresponding author) \\ Yale University \\ Centre for Earth Observation (CEO) \\ Environmental Science Centre \\ 21 Sachem St, New Haven CT 06511, USA \\ Tel: 60-3-8946-7176 E-mail: kamaruz@putra.upm.edu.my
}

\begin{abstract}
Facilities Management (FM) is becoming an increasingly important factor in the built environment. In Malaysia, the field is still in its infancy. This paperwork aims to determine the extent of FM in Malaysia and reviews the changes in the property sector that may positively contribute to opportunities in FM and the challenges that need to be taken into account. In particular, this paper focuses on the changes that are taking place, both at the corporate and at government level. The paper considers issues arising in the local market based on personal observation and discussions with professionals in the property management sector in Malaysia. This review focuses on areas where FM is being actively implemented. This includes discussion on the types of property FM, the management method used and the extent of FM being adopted. The challenges and the opportunities in the local property and construction market are also discussed, specifically to understand the limits of growth for FM. FM is relatively new in Malaysia and much it's the wider concept of FM of building management is still in the process of improving its maintenance management structure. Generally, Integrated Building Management Systems which require an integrated IT advancement and strategic management approach is widely being seen as the improvement of FM in Malaysia. This in fact is the closest definition for FM that is being understood in Malaysia. It may be concluded that until the property management industry fully matures it is unlikely that facility management will be widely practiced for some time in the Malaysian property sector.
\end{abstract}

Keywords: Facilities management, Challenges, Opportunities, Property management, Extent

\section{Introduction}

Facilities management (FM) is now seen in some Asian countries, such as Japan, as an important area in business, and the techniques of FM are increasingly used. As the field of facility management assumes greater importance and as more individuals and organizations become involved, its attendant definitions and descriptions continue to increase. One of the more straightforward of these comes from the international Facility Management Association (IFMA), which defines facility management as "the practice of coordinating the people and the work of an organization into the physical workplace." A more detailed definition is offered by Engineering News-Record:" the discipline of planning, designing, constructing, and managing space-in every type of structure from office buildings to process plants. It involves developing corporate facilities policy, long-range forecasts, real estate, space inventories, projects (through design, construction, and renovation), building operation and maintenance plans, and furniture and equipment inventories."

The Library of Congress seeks to encompass the field's evolution and change by defining facility management as "the 
practice of coordinating the physical workplace with the people and the work of the organization, integrating the principles of business administration, architecture and behavioral and engineering sciences." The International Facilities Management Association (IFMA) gives the following definition: "The practice of coordinating the people and the work of an organization into the physical workplace". A more explicit definition is: An integrated approach to operating, maintaining, improving and adapting the buildings and infrastructure of an organization in order to create an environment that supports the primary objectives of the organization.

The functions of facility management are wide and include the management of real estate, of finance, of change, and of human resources, in addition to services maintenance, domestic services, utilities supplies, security, safety and health and contract management - all of the non-core activities of the organization. Hammer J.M. (1998) has included the following functions; inventory management, programming, master and layout planning, project administration and implementation, purchasing co-ordination, maintenance planning, site management, overall systems coordination. It is a multi-disciplinary function that involves many professionals in the decision-making processes, but to date in Malaysia few are designated 'facility managers'.

\section{What is facility management (FM)?}

FM carries out many definitions but these can be summarized as "the integral managing and execution of housing, services and other means, which contribute to a better performance of the primary process (in relation to effectiveness flexibility efficiency and creativity) in changing surrounding (primary process, market, social and technological) (2). This definition has some practical implications such as an integral management (with an equal accent on both words), a contribution to the core business, a limitation to building occupants, services and other means (equipment) for the workplace and its surroundings, and an ability to cope with changes

Although FM is limited to building occupants, services and other means, the field of activities is very large. In relation to the requirements of the occupancy and the kind of occupants to whom means and services must be delivered, a detailed, tailor made package must be created up. Alternatively, diversity can be constrained by overlapping the packages: certain services are needed everywhere, the way of organizing the services requests a similar approach in attitude to client and to business. The facility management therefore will alternatively operate on three levels - strategic, tactical and operational - and the activities can vary between advising and policy making on one side and managing and executing operations on the other.

\section{FM practice in Asia}

When it comes to FM practice, there is a stark contrast between the Western countries and the Asian Countries. Basically, the field of FM is much more developed and widely being put into practice by property developers / companies in the West. The development of FM is only in Asian countries such as Hong Kong, Malaysia and Singapore and has been developed along three lines, namely practice, research and education. FM has not been readily adopted or encouraged by the Malaysian Government in any organized way.

In Hong Kong, FM has been practiced since 1994 by the local International Facilities Management Association (IFMA) and up to present date, the organization has gone from strength to strength, gaining more members and carrying out successful annual conferences. The whole area of FM is quite well developed with the growth in the professional FM sector being matched and complemented by research and education. The growth of FM has been encouraged by the fact that traditionally Hong Kong has been a place where East meets West and this results to more open ideas along with its multi-cultural dimension. A number of Japanese companies have established FM as part of their organizations; amongst which are the Nippon Telegraph and Telephone Corporation. This company in fact is the first to promote integrated facilities management system through the use of automated mechanization. The Taiwan chapter of IFMA is much smaller than either Hong Kong or Japan but again the overall trend is for an increasing membership. These indicate, together with the well-attended Asian FM conferences, that interest in FM is growing.

FM is described as a very new term in Korea. There the Ministry of Industry and Trade survey found that only 2.7 percent of those surveyed were familiar with the concepts of FM. Although this figure is low, a number of the multi-national companies such as Samsung, Hewlett Packard and IBM Korea had used international FM consultants. The introduction of FM has started in Korea but appears to be developing at a slower pace than some of its competitors in the region. Parallel to the establishment of appropriate Facilities Management guidelines, benchmarking to assess the required quality level is essential. Benchmarking serves both the purposes of helping companies to have an external focus and in finding the industry the best practices by constantly comparing their own performance against that of others. It was found that more than 70 percent of Fortune 500 companies' use benchmarking on a regular basis and benchmarking was quoted as one of the top five most popular business processes. A comprehensive and detailed list of metrics to measure the importance of elements to achieve improved performance had been carried out by precedent researchers in 2000. The study was done on organizations located in 5 countries namely, Australia, Singapore, Hong Kong, Malaysia and Japan. Results of the analysis hinted that the categories of "ground and environment", "size and use 
of facilities" and "energy consumption" were higher than any other categories as listed, indicating that opinions about the "maintenance" was considered as lower importance but energy consumption is lowest in importance compared to other categories. Table 1 as follows listed the results in tabulated form.

\section{$<$ Table 1>}

\section{Facility management practices in Malaysia}

At present, there is no specific leading body for FM in Malaysia. However, the practice of FM in the property area has been widely adopted in recent years. The non-existence of a specific organization to provide guidelines and control on the quality level as well as to assess the performance of FM practice is the reason why evaluations on this field is difficult to analyze. Comparisons thus cannot be made as no specific structure can be used to benchmark the performance of FM practice. As mentioned above, the practice of FM in the Malaysian property sector is being widely adopted by hospitals. Automated computerized system as an integrated approach is the closest to define the adoption of FM. Listed in Table 2 is the type of buildings adopting and practicing FM. Examples of properties using integrated facilities management system are given in the following table.

\section{$<$ Table 2>}

FM in Malaysia is perceived only when building is automatically controlled by computerized software. It should be noted that the uses of dedicated facilities management information technology is only to stimulate advancements in FM. The concept of this is to put forward that a synergistic interaction occurs between the process of FM and the specialist information technology (IT) used for FM. However, the cooperation of this mechanism and of this interaction between specialist FM Information Technology and the process appears to be dependent in the relative capabilities of the process and the IT. Definition of facilities management is poorly understood and thus, it is not being practiced in an appropriate way. Based on research done, the computerized systems used are not only to assist in data monitoring, maintenance tracking as well as space management but at the same time the main concern of use is more on how to ensure monitoring energy of consumption. The scope provided by the computerized systems provides integrated functions that allow the management to manage and to control the following areas only, namely property management, building operation and services management (Facility Planning), maintenance and security. Further research done on several building organizations confirms that a prototype strategic role covering the following aspects is initially adopted to implement the uses of the integrated FM, including formulating and communicating facility policy, planning and designing for continuous improvement of service quality, identifying business needs and user/customer requirements, negotiating service level agreements, establishing effective purchasing and contract strategies, creating service partnership and creating systematic service appraisal in terms of quality, value and risks.

In broad use, facilities management comprises bits and pieces of the above areas, either whole practices or covering only part of the area, i.e. maintenance scope, which are put together in hard copy format. Record or data tracking is poorly or hardly compiled, thus resulting in a poor record of data management, contributing to negative future planning of maintenance works and services management. The practice of facility management in Malaysia at present is undertaken by Real Estate firms. This is due to the fact that buildings such as high rise office towers are managed by property consultants. Property management companies typically provide property and building management services as well as simple operations and maintenance. Their work has traditionally been blue-collar intensive with limited training for operatives. In addition, most companies manage a limited range and number of properties related to their core employer. Hence, with the drive towards a more complex and sophisticated built assets and alignment within the property management sector has come about. A probe into the construction industry shows that no specific FM consultant firms have been established in Malaysia yet but it is envisaged that within these next few years, a positive call will emerge from the changes in the industry.

Recently there have been a number of important ground-breaking FM studies dealing with various topics conducted in Malaysia. This development shows some improvement in defining the importance of adopting FM in Malaysia. A number of research projects are also being carried out by academic institutions with close collaboration of academic and FM practitioners in other countries, thus demonstrating a certain degree of synergy.

The increasing awareness on the importance of a proper maintenance management system becomes the main contributing factor on the development of FM in Malaysia. Subsequent to this, the business management of various organizations has started to promote the need of facilities management as part of the business organization. However, up to the present date, no specific profession has been established in Malaysia. The responsibility of Facilities Manager is often being undertaken by various professionals, especially the Mechanical and Electrical engineers and the Civil engineers. As noted, these professions are not specifically designed to cover the required skills and knowledge of what is expected from the facility managers. In Malaysia, the course of Masters in Facility Management is offered only in University of Teknologi Malaysia(UTM) and in Universiti Teknologi MARA, Shah Alam ( UiTM). These courses took students from various backgrounds, particularly those from the construction line as the pioneers for this field. Specific 
subjects on Maintenance Management and FM are also designed for students in Building Surveying program in UiTM and University Malaya (UM)

\section{Development of FM in Malaysia}

\subsection{Problems of FM Implementation}

In broad term, the main problem of FM adopted and implemented in Malaysia concerns the organizational response to the needs of FM in the property industry. It should be noted that the beneficiaries of any facility provided in a property require direct response and participation of the community that the facility is provided for. Response comes in the manner where the community is allowed to have a say in the decisions concerning the facility, and where possible to take part in its development and manage it on completion. This can be achieved through community participation, which according to Cernea (1985) is defined as "an active process by which beneficiary client groups influence the direction and execution of a development project with a view to enhancing their well-being in terms of income, personal growth, self-reliance or other values they cherish". Joint or collaborative involvement of the government appears through the imposition of guidelines and research works as well as assistance in complying to the requirements.

In short, the problems of FM implementation in Malaysia, based on the observation are summarized as follows, namely (a) Lack of participation from the whole organization due to lack of understanding on the importance of providing a comprehensive FM in order to achieve the objectives of this concept, (b) Lack of technical knowledge and expertise on handling the problems often occur, thus the need to design a flexible FM planning, the need to manipulate the advantages and benefits of using FM and the need to provide immediate responses for arising problems, (c) The lack of proper FM guidelines and requirements in Malaysia that can be used to measure the quality and performance of FM practices by company as well as to standardize the practice and implementation., and (d) Non-existence of specific FM association to monitor the progress of FM being practiced by property management or consultants in Malaysia.

The failures found in the adoption and implementation of FM in Malaysia can be categorized into four factors as described in Table 3 .

\section{$<$ Table 3>}

\subsection{Changes}

Malaysia's economic growth is driven by four factors, including (a) A high savings rate, which supports vigorous rates of investment and capital accumulation, (b) Structural change, which has been both the cause and effect for growth, e.g. the shift in economic and industrial sectors, (c) Pragmatic and incremental reforms resulting in a move from a planned economy to achieve Vision 2020, (d) Economic conditions, e.g. the "advantages of backwardness" whereby growth is related, and (e) to the changes in the global economy.

Looking at a minor context, the changes that may boost the implementation of the FM can be summarized as follows: (a) The changes in the social perception in which a well-maintained building is much more sought after by potential tenants or buyers. This has resulted in a need to plan and to design suitable management approach that may suit the needs of the buyers/tenants, (b) The changes in the services offered for new development where integrated system (computerized system) is much preferred by potential tenants/buyers. As mentioned earlier, automated building services required computerized automation and this supports the development of FM in building management, and (c)There has been constant improvement in the technology sector. The progressive changes in technology has seen more and more new technologies being made available in Malaysia and the implementation or adoption of these new technologies often require advancement in management system and IT system. It is noted that most of the modern technologies are of integrated system, requiring IT technology in order to operate them.

\subsection{Opportunities}

The subject of FM is still new in Malaysia and this provides greater opportunities as these have not been established and therefore many areas of FM are more flexible for different techniques and approach practices than in other countries. The opportunities for FM development in Malaysia arise from the following issues, namely (a) the slow economic pace in Malaysia has resulted in slow construction development. Acknowledging the need to increase the construction sector, the government has encouraged consultants and contractors to get involved in more specialized areas, especially in maintenance works and management of services, facades as well as conservation works in order to ensure that this sector becomes much more competitive in the global world, and (b) the maintenance and services rates are becoming high in Malaysia and FM is seen as a substitute for strategic and proper management that can control and manage overall building costs. In addition to this, FM also provides strategic planning that records all relevant data specific to FM area, (c) for many leading participants in the outsourcing industry today, the well understood tools of performance based or incentive contracting and improved techniques for operational management are now taken for granted as the starting point for services delivered. The top players on both the in-house and industry supply side are now increasingly responding to core business needs. They are doing this by addressing a more strategic challenge using the concepts 
within the construction industry to construct service agreements that free core business capital tied up in facilities at the same time reducing costs and increasing quality, (d) In several city centres, such as Kuala Lumpur and Johor Bahru, the city areas are considered dense and compact, disallowing any future construction development to take place. Thus the buildings located within the city centres are forced to be maintained as the cost of demolition is very high. In addition to this, the cost of services and maintenance is also high and therefore FM is seen as an approach to minimize high maintenance cost that may occur due to poor maintenance in the past., (e) Another arising issue is the inability of property or building management to collect the rental rate for space rented, services and bills from the tenants, contributing to insufficient funds to pay for necessary bills. FM is practiced as this can ensure that rental can be collected as a stipulated date, as the failure to provide the rental fee may result in disconnection of services, such as Mechanical and Electrical provided to the tenants.

\section{Challenges}

The real challenges for FM to be thoroughly implemented in buildings lies in the following areas:

(a) The non-existence of standards that can be used to measure the quality level and performance of both traditional and integrated FM applied by the building/property management. The current situation in Malaysia confirms that practices vary from one organization to another, depending on the services provided or applied for the buildings. The slow pace of regulating appropriate FM standard or regulation is another factor that requires immediate response and action.

(b) Lack of local expertise to provide immediate response to failure of service as well as lack of FM practitioners in the local market that can provide advice or assistance in the implementation of FM. Property skills are vital, but the local industry remains conservative and protective. A change in the mindset is needed and therefore more proactive campaigns are needed to change the perception of the professionals involved in the construction and property markets.

(c) The implementation of FM is considered late for some properties as at present, there are many aging buildings with high deterioration level. FM may help in standardizing future maintenance allocation required but this, however, may not contribute to minimization of maintenance cost if the building services are in poor condition due to improper maintenance carried out in the past.

(d) Malaysia is still lagging behind in the aspect of software development specific to FM and adoption of integrated FM may require high initial cost, unless the computerized programmes can be found locally in the market. Most building management claim that their profits are not as much as expected and in order to adopt this integrated system, funding support is required.

The adoption of an integrated FM requires space allocation in order to store the automation mechanism to operate the integrated services system. This may not be a problem for new developments but as earlier mentioned there are lots of aging buildings and densely populated buildings. Allocation of the monitoring units may need some adjustments and reshuffling of the existing services, furthermore costly renovation works might have to take place.

\section{Conclusion and Recommendations}

The formal practice of facility management as a recognized discipline is a new phenomenon and as such is vulnerable. This area is hardly recognized in Malaysia even among the building administrative professions. However, FM as a discipline merged out of practice due to the need to focus on the elaborate and expensive facilities which crucially support the activities of most of today's organizations. It is a distinctive part of the overall management function and borrowing from the concept of business process analysis as is the process that provides the working environment in which an organization functions.

Offices and hospitals appear to have dominated the attention of the facility management profession in Malaysia. Other facilities are seldom seriously considered. Traditional management methods are dominantly applied compared to integrated FM system although the new approach proves positive strategic operations. Again, the common factor in all of this lies in the integration by the facility manager of all of the support roles which provides a working environment for an organization. The lack of local expertise as well as the disaggregated deployment of specialists cannot meet the challenges in Malaysia at present time. More efforts are required to open the eyes of the industry as well as the public and professional bodies. To be more flexible or less protective, this requires participation from all sectors and positive responses from the government

\section{References}

Daniel, C.W. H., Edwin H.W. C., Nicole Y.W. and Man-Wai, C (2000) Significant Metrics For Facilities Management Benchmarking In The Asia Pacific Region; Facilities Volume 18 - Number 13/14, MCB University Press, pp. 545-555.

FM. (2003). Discovering the path to advanced FM $29^{\text {th }}$ to $30^{\text {th }}$ April 2003, Hotel Nikko, Kuala Lumpur.

Hans Brat, J.M (1996), Development In The Management Of Facilities At Large Corporations, Facilities Volume 14 Number 5/6, MCB University Press, pp. 39-47. 
Lomas, D.W. (1999) Facilities Management In Hong Kong; Facilities Volume 17 - Number 12/13, MCB University Press, pp. 470-475.

Nutt, B. and McLennan, P. (2000), Facility Management - Risks and Opportunities, Blaskwell Science.

Syed Abdul Harris Syed Mustapa (2001) Facilities Management of The Intelligent Building, unpublished thesis, University Teknologi MARA, Shah Alam.

Table 1.Analysis of results

\begin{tabular}{|l|l|l|l|}
\hline & Name of metric & $\begin{array}{l}\text { Average Importance } \\
\text { Rating }\end{array}$ & Mean Standard Deviation \\
\hline 1 & Cleaning & 3.78 & 1.06 \\
\hline 2 & Refurbishment & 3.78 & 1.09 \\
\hline 3 & Parking & 3.76 & 1.06 \\
\hline 4 & Ground and environment & 3.66 & 1.14 \\
\hline 5 & Size and use of facilities & 3.64 & 1.28 \\
\hline 6 & Safety and security & 3.59 & 0.99 \\
\hline 7 & Maintenance & 3.54 & 0.89 \\
\hline 8 & Energy consumption & 3.49 & 1.23 \\
\hline
\end{tabular}

Table 2. List of properties adopting integrated FM (computerized system).

\begin{tabular}{|c|c|c|c|c|}
\hline & Category & Property & Facilities System Used & Examples \\
\hline \multirow[t]{3}{*}{1} & $\begin{array}{l}\text { Service } \\
\text { Amenities }\end{array}$ & Hospital & $\begin{array}{l}\text { THIS (Total Hospital Integrated } \\
\text { System }\end{array}$ & $\begin{array}{l}\text { Selayang Hospital, Putrajaya } \\
\text { Hospital }\end{array}$ \\
\hline & & Warehouse & $\begin{array}{l}\text { CAFM (Computerized Aided } \\
\text { Facilities Management }\end{array}$ & KLIA Cargo, MIMOS \\
\hline & & Hotels & $\begin{array}{l}\text { BUS (Building Automation } \\
\text { System) }\end{array}$ & $\begin{array}{l}\text { Pan Pacific KLIA, Le } \\
\text { Meridian }\end{array}$ \\
\hline 2 & Business & $\begin{array}{l}\text { High-Rise Office } \\
\text { Tower }\end{array}$ & $\begin{array}{l}\text { BUS (Building Automation } \\
\text { System) }\end{array}$ & $\begin{array}{lrr}\text { Petronas } & \text { Twin } & \text { Tower , } \\
\text { Central } & \text { Plaza, } & \text { Telekom } \\
\text { Tower } & & \end{array}$ \\
\hline 3. & Commercial & $\begin{array}{l}\text { Shopping } \\
\text { Complex }\end{array}$ & $\begin{array}{l}\text { BUS (Building Automation } \\
\text { System) }\end{array}$ & KLCC, KL Sentral \\
\hline 4. & Residential & Condominium & Smart Home System & KL Sentral, Cyberjaya \\
\hline
\end{tabular}


Table 3. Facilities management failures on managing building features

\begin{tabular}{|l|l|l|}
\hline & Failing Factors & Description \\
\hline 1. & Tactical Failings & Inadequate performance standards \\
\hline & & Low maintenance of cleaning standards \\
\hline 2. & $\begin{array}{l}\text { Strategic Environmental } \\
\text { Failings }\end{array}$ & Lack of building performance monitoring data \\
\hline & & Failure to anticipate the consequences of change \\
\hline & & Failure to understand the non-linear nature of building complexity \\
\hline 3. & Tactical Cultural Failings & Slow response of systems used \\
\hline & & Responding slowly to complaints \\
\hline & & Ignorance job stress \\
\hline 4. & Strategic Cultural Failings & $\begin{array}{l}\text { Failure to provide appropriate advise on design and planning based on } \\
\text { overall performance }\end{array}$ \\
\hline & & Facilities management issues not prioritized \\
\hline & & $\begin{array}{l}\text { Over reliance on automated systems used } \\
\text { background improvement due to lack in technical knowledge and }\end{array}$ \\
\hline
\end{tabular}

